\title{
Tuberculosis in HIV-infected persons in the context of wide availability of highly active antiretroviral therapy
}

\author{
E. Girardi*, G. Antonucci ${ }^{\#}$, P. Vanacore*, F. Palmieri\# ${ }^{\#}$ A. Matteelli ${ }^{\oplus}$, E. Iemoli $^{+}$, S. Carradori $^{\S}$, \\ B. Salassa ${ }^{f}$, M. Bruna Pasticci**, M.C. Raviglione ${ }^{\# \#, ~ G . ~ I p p o l i t o *, ~ a n d ~ t h e ~ G I S T A-S I M I T ~ S t u d y ~ G r o u p ~}$
}

Tuberculosis in HIV-infected persons in the context of wide availability of highly active antiretroviral therapy. E. Girardi, G. Antonucci, P. Vanacore, F. Palmieri, A. Matteelli, E. Iemoli, S. Carradori, B. Salassa, M. Bruna Pasticci, M.C. Raviglione, G. Ippolito, and the GISTA-SIMIT Study Group. C ERS Journals Ltd 2004.

ABSTRACT: Highly active antiretroviral therapy (HAART) greatly reduces the risk of developing tuberculosis for HIV-infected persons. Nonetheless, HIV-associated tuberculosis continues to occur in countries where HAART is widely used.

To identify the characteristics of HIV-infected persons who develop tuberculosis in the context of the availability of HAART, the current authors analysed data taken from 271 patients diagnosed, in Italy, during 1999-2000. These patients represent $0.7 \%$ of the 40,413 HIV-infected patients cared for in the clinical units participating in this current study.

From the data it was observed that 20 patients $(7.4 \%)$ had a previous episode of tuberculosis whose treatment was not completed. Eighty-one patients $(29.9 \%)$ were diagnosed with HIV at tuberculosis diagnosis, $108(39.8 \%)$ were aware of their HIV status but were not on antiretroviral treatment and $82(30.3 \%)$ were on antiretroviral treatment. Patients on antiretroviral treatment were significantly less immunosuppressed than patients with HIV diagnosed concurrently with tuberculosis, or other patients not on antiretrovirals (median CD4 lymphocytes count: 220 cells $\cdot \mathrm{mm}^{-3}$ versus 100 cells $\cdot \mathrm{mm}^{-3}$, and 109 cells $\cdot \mathrm{mm}^{-3}$, respectively). No significant differences in clinical presentation of tuberculosis according to antiretroviral therapy status were recorded.

Failure of tuberculosis control interventions (e.g. noncompletion of treatment) and of HIV care (delayed diagnosis of HIV infection and suboptimal uptake of therapy) may contribute to continuing occurrence of $\mathrm{HIV}$-associated tuberculosis in a country where highly active antiretroviral therapy is largely available. However, a significant proportion of cases occur in patients who are on antiretroviral treatment.

Eur Respir J 2004; 24: 11-17.
*Dipartimento di Epidemiologia, and ${ }^{*}$ Dipartimento Clinico, Istituto Nazionale per le Malattie Infettive "L. Spallanzani" - IRCCS, Rome, "Clinica Malattie Infettive e Tropicali, Università di Brescia, Brescia, ${ }^{+}$III Divisione di Malattie Infettive, Ospedale "L. Sacco", Milano, ${ }^{\S}$ Divisione di Malattie Infettive, Arcispedale S. Anna, Ferrara, ${ }^{f}$ Divisione di Malattie Infettive B, Ospedale Amedeo di Savoia, Torino, and **Istituto di Malattie Infettive, Università di Perugia, Perugia, Italy.

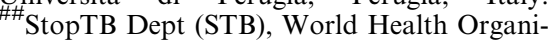
zation, Geneva, Switzerland.

Correspondence: E. Girardi, Dipartimento di Epidemiologia, Istituto Nazionale per le Malattie Infettive "L. Spallanzani" - IRCCS, via Portuense, 292-00149 Roma, Italy. Fax: 39065582825

E-mail: girardi@inmi.it

Keywords: Antiretroviral therapy, epidemiology, HIV infection, Italy, multicentre study, tuberculosis

Received: September 262003

Accepted after revision: March 232004

This work was financially supported by Ministero della Salute-Progetto AIDS-ISS grant 50.A.0.20 and Fondi per la Ricerca Corrente degli IRCCS.
Infection with HIV is the most potent risk factor for progression from latent or newly acquired tuberculosis infection to active disease [1]. However, recent observational studies conducted both in low and high tuberculosis incidence countries have consistently shown that the risk of developing tuberculosis is decreased by $70-90 \%$ for $\mathrm{HIV}$-infected persons who receive highly active antiretroviral therapy (HAART) compared with untreated patients [2-5]. As a consequence, incidences of $\mathrm{HIV}$-associated tuberculosis have generally decreased in countries were HAART has become a standard of care for HIV-infected persons. Nonetheless, HIV-associated tuberculosis also continues to occur in the context of a wide use of HAART [6, 7]. Surveillance data suggest that among patients who develop AIDS, the proportion of patients with tuberculosis is higher among those who are treated with HAART and are less immunosuppressed, compared with those who have major immunosuppression in spite of HAART, or are not treated [8]. Finally, there is some evidence that clinical presentation of HIV-associated tuberculosis may also have changed after the introduction, in clinical practice, of the use of HAART [9].
Identification of the characteristics of HIV-infected persons who still develop tuberculosis in countries were there is large availability of HAART can provide further insight into the potential effects of the widespread use of antiretroviral therapy on the tuberculosis/HIV epidemics, and help to design control interventions. The aim of this study was to assess the occurrence of HIV-associated tuberculosis after HAART came into widespread use and to analyse epidemiological and clinical characteristics of patients presenting with this disease.

\section{Patients and methods}

\section{Study design and selection of subjects}

The authors analysed data on HIV-infected patients who presented with tuberculosis in Italy in 1999-2000 and who were enrolled in a nationwide multicentre, prospective, observational study designed to evaluate outcomes of therapy of HIV-associated tuberculosis in the era of HAART [9]. In particular, the authors aimed to analyse the history of 
previous tuberculosis and antiretroviral treatments amongst patients with tuberculosis, and to identify possible differences between patients diagnosed with tuberculosis while receiving or not receiving antiretrovirals.

The study was a collaboration between the Italian Study Group on Tuberculosis and AIDS (Gruppo Italiano di Studio Tubercolosi e AIDS: GISTA) and the Italian Society for Infectious and Tropical Diseases (SIMIT). All of the 154 Italian infectious disease hospital units were invited to participate in the study. The authors chose to carry out this study in these units since the Italian National Health Service regulations dictate that AIDS patients and HIV-infected persons receiving antiretroviral therapy receive care in designated infectious disease units. In Italy, HIV care, including administration of antiretrovirals, is provided free of charge.

Individuals (in- and outpatients) $\geqslant 18$ yrs old, with confirmed HIV infection, who were diagnosed with tuberculosis in participating units between 1 May 1999 and 30 September 2000 , were included in the study. In the present paper the authors analysed the data collected at the time of diagnosis of tuberculosis for the enrolled patients.

Each of the participating centres sought ethical clearance according to local regulations.

\section{Data collection}

At baseline, the following data were collected for each enrolled patient: age; sex; country of birth; place of residence; education; employment; date of first positive HIV test; HIVtransmission category; history of active tuberculosis; history of tuberculin skin test; history of treatment for active or latent tuberculosis; recent close contact with infectious tuberculosis; results of chest radiographs; and clinical evaluation and microbiological examinations for mycobacteria. Data on current antiretroviral therapy, CD4 lymphocyte count, plasma HIV RNA and HIV clinical status were also recorded. For patients who had been diagnosed with HIV at least 3 months before tuberculosis, the authors also collected data on prior antiretroviral treatments and the lowest CD4 lymphocyte count available. Each participating unit also provided the overall number of HIV-infected patients cared for during the study period.

All data were collected onto coded standardised forms. All forms were checked by scientific staff at the coordinating centre (National Institute for Infectious Diseases "L. Spallanzani", Rome, Italy) for logical errors.

\section{Definitions}

A case of tuberculosis was defined as a physician diagnosis of tuberculosis in a person who had bacteriological evidence of active disease (isolation of Mycobacterium tuberculosis from a clinical specimen and/or demonstration of $M$. tuberculosis from a clinical specimen by nucleic acid amplification) and/or signs and symptoms compatible with tuberculosis (e.g. abnormal, unstable chest radiographs or clinical evidence of current disease) and completed diagnostic evaluation.

On the basis of clinical and microbiological findings, tuberculosis was classified as pulmonary, both pulmonary and extrapulmonary, and extrapulmonary. Among patients with pulmonary involvement, the chest radiograph pattern was classified as: "upper-lobe infiltrate/cavitation"; "lower-lobe infiltrate"; "pleural effusion"; "miliary/interstitial pattern"; and "other" (including normal chest radiographs).

Diagnosis of HIV infection was defined concurrent with diagnosis of tuberculosis if patients had a first HIV-positive test within 3 months from tuberculosis diagnosis.

Patients were considered to have received antiretroviral therapy if they took antiretrovirals for a minimum of 3 months and were defined on antiretroviral therapy at the time of tuberculosis diagnosis if they received antiretrovirals for a minimum of 3 months in the 6 months preceding tuberculosis diagnosis.

\section{Statistical analysis}

Descriptive statistical methods were used to provide a general profile of the study population. The Chi-squared test was used to compare proportions and nonparametric MannWhitney U-test was used to compare continuous variables. Logistic regression analysis was used to identify factors independently associated with a diagnosis of HIV infection concurrent with diagnosis of tuberculosis. Statistical analyses were performed using standard statistical software.

\section{Results}

From 154 clinical units invited to participate in the study, $96(62.3 \%)$ agreed. These units are located in 18 of Italy's 20 regions, and all of them are located in public hospitals, 19 of which are university teaching hospitals.

During the study period, 271 HIV-infected patients were diagnosed with tuberculosis in the participating centres. These patients represented $0.7 \%$ of the $40,413 \mathrm{HIV}$-infected patients that were under care in participating units during the same time period. Diagnosis of tuberculosis was confirmed by isolation of $M$. tuberculosis in culture in 183 patients $(67.5 \%)$ and by detection of nucleic acids of $M$. tuberculosis in a further 21 patients $(7.7 \%)$. Characteristics of the patients enrolled are shown in table 1.

From the patients enrolled, $45(16.6 \%)$ reported a previous episode of tuberculosis, which had been diagnosed a median of 27 months before the current episode. Among these

Table 1.-Characteristics of 271 HIV-infected patients diagnosed with tuberculosis

\section{Patient characteristics}

\begin{tabular}{lc}
\hline Age yrs median (IQR) & $37(32-41)$ \\
Sex & \\
$\quad$ Male & $221(81.5)$ \\
Female & $50(18.5)$ \\
Place of birth & \\
$\quad$ Italy & $177(65.3)$ \\
Other & $94(34.7)$ \\
HIV transmission category & \\
IDUs & $130(48.0)$ \\
Heterosexual contacts & $76(28.0)$ \\
MSM & $39(14.4)$ \\
Other/undefined & $26(9.6)$ \\
Localisation of TB & \\
Pulmonary & $150(55.8)$ \\
Pulmonary+extrapulmonary & $69(25.4)$ \\
Extrapulmonary & $52(19.1)$ \\
CD4 lymphocyte count cells·mm ${ }^{-3}$ median (IQR) & $120(44-284)$ \\
Previous episode of tuberculosis & $45(16.6)$ \\
Previous treatment for latent TB infection & $3(1.5)$ \\
\hline
\end{tabular}

Data are presented as $\mathrm{n}(\%)$ unless otherwise indicated. TB: tuberculosis; IQR: interquartile range; IDUs: injecting drug users; MSM: males who have sex with males. 
patients, $20(7.4 \%)$ had not completed the treatment for the previous episode of tuberculosis. A total of 19 patients $(7 \%)$ reported a previous positive tuberculin skin test, of these three $(1.1 \%)$ had a course of isoniazid, of at least 6 months, as treatment for latent tuberculosis infection prior to diagnosis of active tuberculosis.

Distribution of patients by knowledge of HIV serostatus and antiretroviral treatment prior to diagnosis of tuberculosis is shown in figure 1. Patients who were diagnosed with HIV concurrently with diagnosis of tuberculosis represented $29.9 \%$ (81 out of 271) of the patients enrolled. When demographic and epidemiological characteristics of these patients were compared with those of other patients, being foreign born (born outside Italy), being male and being in HIV transmission

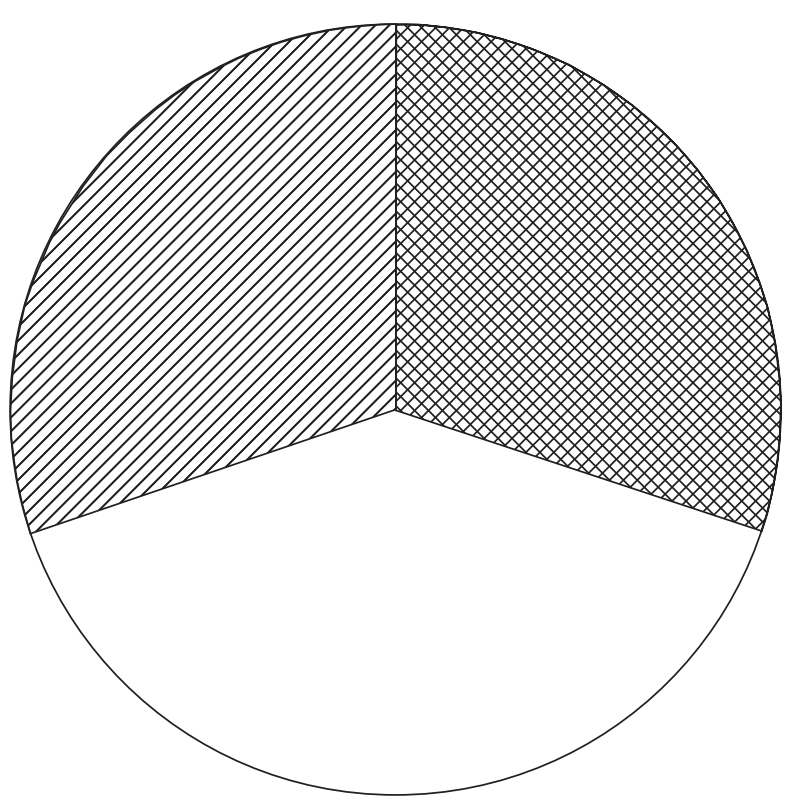

Fig. 1.-Distribution of $271 \mathrm{HIV}$-infected patients by previous knowledge of HIV serostatus and antiretroviral therapy at the time of diagnosis of tuberculosis (TB). HIV diagnosed concurrently with TB (29.9\%); $\square$ : HIV diagnosed before TB/not on highly active antiretroviral therapy (HAART; $39.9 \%$ ); $\mathbb{Z}$ : on HAART $(30.2 \%)$. categories other than intravenous drug users were found to be independently associated with a diagnosis of HIV infection at the time of diagnosis of tuberculosis (table 2).

Among the 108 patients known to be HIV seropositive, who were not on antiretroviral treatment at the time of diagnosis with tuberculosis, 86 had never received antiretrovirals while the remaining 22 patients had received antiretroviral therapy for 3-81 months, but not in the 6 months preceding diagnosis of tuberculosis. For these patients the last antiretroviral regimen was: triple combination therapy for 11 patients; dual combination therapy for six patients; and monotherapy for one patient. Data concerning the remaining four patients were incomplete.

A total of 82 patients $(30.3 \%$ of those enrolled) were on antiretroviral treatment at the time of diagnosis of tuberculosis. These patients had been on antiretroviral treatment for a median of 27 months prior to tuberculosis diagnosis. The patients last antiretroviral regimen included four drugs in the case of six patients, three drugs in the case of 62 patients and two drugs in the case of 12 patients, while data were incomplete for two of the patients. Data on the lowest recorded CD4 count were not available for 10 of these patients. Among the remaining 72 patients the median lowest recorded CD4 lymphocyte count was 80 cells $\cdot \mathrm{mm}^{-3}$, the median gain in CD4 lymphocyte count was 81 cells $\cdot \mathrm{mm}^{-3}$ and 31 out of 72 patients $(43.1 \%)$ had a CD4 lymphocyte count $\geqslant 100$ cells $\cdot \mathrm{mm}^{-3}$ above the nadir value at the time of tuberculosis diagnosis.

When the authors compared patients grouped on the basis of prior knowledge of HIV serostatus and antiretroviral treatment, they found that the median CD4 lymphocyte count at the time of diagnosis of tuberculosis for patients on antiretroviral therapy $\left(220\right.$ cells $\left.\cdot \mathrm{mm}^{-3}\right)$ was significantly higher than that recorded among patients not on therapy (109 cells $\cdot \mathrm{mm}^{-3}$ ) and among those who were diagnosed with HIV concurrently to diagnosis of tuberculosis $\left(100\right.$ cells $\left.\cdot \mathrm{mm}^{-3}\right)$ ( $\mathrm{p}<0.01$ using the Mann-Whitney U-test for both comparison); no significant difference was observed between the two latter groups (fig. 2).

As shown in table 3, among patients on antiretroviral therapy the authors observed a slightly higher proportion of cases with pulmonary involvement only, although the difference was not statistically significant. In addition, no significant differences were observed in chest radiograph pattern among the 215 patients with pulmonary involvement.

Table 2. - Proportion of patients with diagnosis of HIV infection concurrent with diagnosis of tuberculosis (TB) by demographic and epidemiological characteristics

\begin{tabular}{|c|c|c|c|}
\hline Patient characteristics & No. with concurrent HIV-TB diagnosis/total (\%) & Adjusted odds ratio $\#(95 \% \mathrm{CI})$ & p-value \\
\hline Patients $\mathrm{n}$ & $81 / 271$ & & \\
\hline \multicolumn{4}{|l|}{ Sex } \\
\hline Male & 65/221 (29.4) & $3.46(1.34-8.91)$ & 0.01 \\
\hline Female & $16 / 50(32.0)$ & 1.00 (ref.) & \\
\hline \multicolumn{4}{|l|}{ Age yrs } \\
\hline $20-30$ & $24 / 43(55.8)$ & $1.03(0.37-2.88)$ & NS \\
\hline $31-40$ & $32 / 137(27.5)$ & $0.51(0.24-1.09)$ & NS \\
\hline$>40$ & $25 / 91(27.5)$ & 1.00 (ref.) & \\
\hline \multicolumn{4}{|l|}{ Country of birth } \\
\hline Italy & 28/177 (15.3) & 1.00 (ref.) & \\
\hline Other & $54 / 94(57.4)$ & $4.71(2.19-10.11)$ & $<0.001$ \\
\hline \multicolumn{4}{|l|}{ HIV transmission category } \\
\hline IDUs & $11 / 130(8.5)$ & 1.00 (ref.) & \\
\hline Heterosexual contacts & $34 / 76(44.7)$ & $6.67(2.88-15.45)$ & $<0.001$ \\
\hline MSM & $18 / 39(46.2)$ & $3.72(1.39-10.01)$ & 0.009 \\
\hline Other/unknown & $18 / 26(69.2)$ & $21.68(6.54-71.89)$ & $<0.001$ \\
\hline
\end{tabular}

IDUs: injecting drug users; MSM: males who have sex with males. ${ }^{\#}$ : estimated in a logistic regression model including the variables listed in the table. 


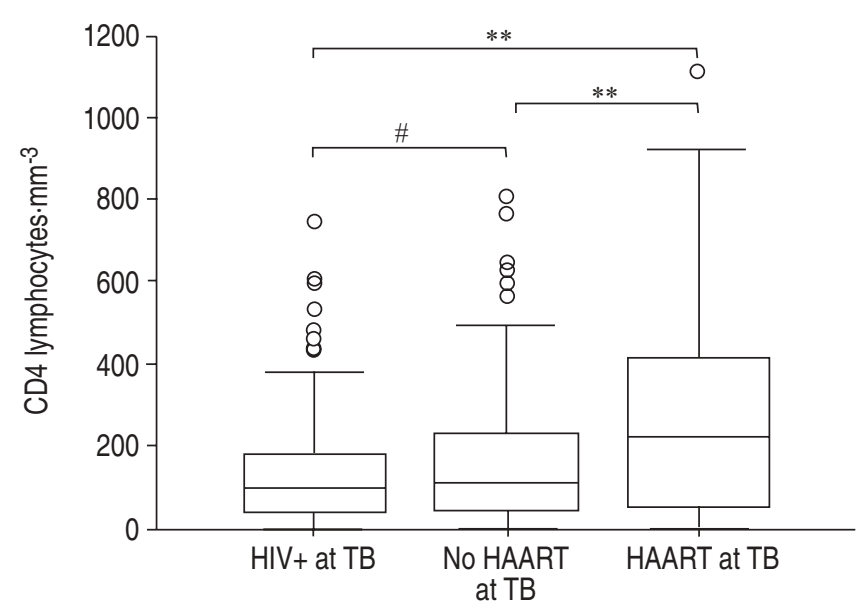

Fig. 2.-CD4 lymphocytes count in $271 \mathrm{HIV}$-infected patients at the time of diagnosis of tuberculosis (TB) by previous knowledge of HIV serostatus and antiretroviral therapy status. The median value (-), interquartile range and outliers are shown. Mann-Whitney U-test was used for statistical comparisons. HIV+ at TB: HIV infection diagnosed concurrently with TB $(n=81)$; no HAART at TB: not on antiretroviral therapy at TB diagnosis $(n=108)$; HAART at TB: on antiretroviral therapy at TB diagnosis $(n=82)$. **: $p<0.01{ }^{*}: \mathrm{p}>0.05$.

Table 3.-Localisation of tuberculosis (TB) and chest radiograph pattern in patients with pulmonary involvement by antiretroviral therapy at the time of diagnosis of TB

\begin{tabular}{lcc}
\hline & \multicolumn{2}{c}{$\begin{array}{c}\text { Antiretroviral therapy at } \\
\text { the time of diagnosis of TB }\end{array}$} \\
\cline { 2 - 3 } & \multicolumn{1}{c}{ Yes } & No \\
\hline $\begin{array}{l}\text { Patients n } \\
\text { Localisation of TB }\end{array}$ & 82 & 189 \\
$\quad$ Pulmonary & $50(61.0)$ & $100(52.9)$ \\
$\begin{array}{l}\text { Pulmonary+extrapulmonary } \\
\text { Extrapulmonary }\end{array}$ & $15(18.3)$ & $54(28.6)$ \\
Chest radiograph pattern & $17(20.7)$ & $35(18.5)$ \\
$\quad$ Upper-lobe infiltrate/cavitation & $16(23.2)$ & $45(26.6)$ \\
$\quad$ Lower-lobe infiltrate & $9(13.0)$ & $24(14.2)$ \\
Pleural effusion & $8(11.6)$ & $18(10.7)$ \\
$\quad$ Miliary/interstitial & $16(23.2)$ & $36(21.3)$ \\
Other & $20(29.0)$ & $46(27.2)$ \\
\hline
\end{tabular}

Data are presented as $\mathrm{n}(\%)$. ${ }^{\#}$ : among 216 patients with pulmonary involvement and available results of chest radiograph.

\section{Discussion}

In this multicentre study conducted in Italy during 1999-2000, it was observed that 271 HIV-infected patients presenting with tuberculosis represented $0.7 \%$ of the overall number of $\mathrm{HIV}$-infected patients cared for in participating clinical units during the study period. In a previous multicentre survey, conducted in Italy, the authors found that in 1989 patients with active tuberculosis represented $2.3 \%$ of the total number of HIV-infected patients under care [10]. Although the results from the two studies are not strictly comparable, the present results strongly suggest a marked decrease in the frequency of tuberculosis among HIV-infected patients. This finding is in agreement with the results of cohort studies that demonstrate that HIV-infected patients treated with HAART, which entered into clinical use in Italy in 1996, have an 80-90\% reduction in the risk of developing tuberculosis [2-5]. Nevertheless, the current results show that
HIV-infected patients continue to constitute a significant proportion of patients diagnosed with tuberculosis in Italy. In fact, patients enrolled in this study represent $6.9 \%$ of the 3,931 tuberculosis cases reported during the study period in the Italian provinces where participating units are located [11]. This proportion may be considered a minimum estimate since HIV testing is not performed routinely in tuberculosis patients in Italy, and some HIV-associated tuberculosis cases may have been cared for in clinical units other than those participating in this study.

The present study suggests that several factors, related to deficiencies either in tuberculosis control interventions or in delivering HIV care, may contribute to the continuing incidence of HIV-associated tuberculosis in the context of a wide availability of HAART. In addition, the results of the current study suggest that, in some instances, immune reconstitution, due to antiretroviral therapy, may not be sufficient to prevent occurrence of active tuberculosis.

First of all, only $15.8 \%$ of the patients in the current study who reported a previous positive tuberculin skin test received a treatment for latent tuberculosis infection. This observation is in agreement with results of studies conducted in Italy and in the USA $[12,13]$, which demonstrated the underuse of screening and treatment of latent tuberculosis infection for HIV-infected persons. In addition $15 \%$ of cases were observed among persons who reported a previous episode of tuberculosis. Importantly, almost half of these patients had not completed a course of treatment following the previous diagnosis of tuberculosis. Incomplete treatment of active tuberculosis has been one of the major factors contributing to the resurgence of tuberculosis in industrialised countries [14] and the current author's preliminary results of the follow-up of this cohort of patients suggests the persistence of a high rate of noncompletion of treatment among HIV-infected persons in an industrialised country setting [9].

Almost $30 \%$ of patients in the current series were diagnosed with HIV infection at the time of the diagnosis of tuberculosis or shortly before. Thus, these patients missed the opportunity to receive, during the asymptomatic phase of HIV infection, an antiretroviral treatment that could have prevented the deterioration of their immune status and reduced their risk of tuberculosis. A high proportion of patients unaware of their HIV status at the time of tuberculosis diagnosis has also been observed in the USA and the UK $[15,16]$, and recent studies suggest that a delayed diagnosis of HIV infection has become increasingly common in industrialised countries among patients with an AIDS-defining illness [17, 18]. The high proportion of patients with a delayed diagnosis of HIV infection among the foreign born may reflect a lack of knowledge about AIDS and/or a reduced access to medical services while the association between sex and delayed diagnosis may be due to the fact that females may be more likely to be actively offered HIV testing, for example at the time of pregnancy [19]. The low proportion of patients unaware of HIV status among drug users may reflect that HIV testing is actively offered in drug treatment centres in Italy with a rate of acceptance of $\sim 80 \%$ [20].

Among the patients who tested positive for HIV at least 3 months before the diagnosis of tuberculosis, more than a half were not on antiretroviral therapy. This group of patients was quite heterogeneous. Approximately one quarter were treated in the past but did not receive antiretrovirals for at least 6 months before diagnosis of tuberculosis. Of those who never received antiretrovirals, $60 \%$ had a CD4 lymphocyte count $<200$ cells $\cdot \mathrm{mm}^{-3}$ at the time of tuberculosis and, according to current guidelines [21], should have been prescribed antiretrovirals. The current authors do not have enough information in this study to identify reason why these patients were not treated or had interrupted treatment. However, the 
present authors hypothesise that low adherence to care or delayed presentation for care to medical centres may have contributed to this phenomenon.

A significant proportion of tuberculosis cases among patients who did receive antiretroviral therapy, and among patients who had a good immunological response to antiretroviral therapy, was observed. Patients who had tuberculosis when on antiretroviral therapy were significantly less immunosuppressed than untreated patients. These observations are consistent with data from other studies conducted in Europe and in the USA showing that HIVassociated tuberculosis tends to occur at higher CD4 cells count in the context of a wide use of HAART [7, 22] and may have different explanations.

Tuberculosis, unlike other HIV-associated opportunistic infections, may also occur at relatively high levels of CD4 lymphocytes count [23], although its frequency markedly increases in patients with more severe immunosuppression [24]. It is possible that among HAART-treated patients, although the risk of developing tuberculosis is greatly reduced, the relative proportion of patients with higher CD4 lymphocytes increases, resulting in a relative increase of tuberculosis cases among patients who are less immunosuppressed and thus in an increase in the median CD4 lymphocytes count at the time of diagnosis of tuberculosis.

On the other hand, the occurrence of tuberculosis in patients on HAART at higher CD4 lymphocyte counts may reflect, in part, an incomplete immune restoration. In fact, although it has been demonstrated that HAART can induce restoration of in vitro response to mycobacterial antigen [25], studies conducted in patients co-infected with HIV and tuberculosis suggest that recovery of cellular immunity against tuberculosis may be delayed, incomplete or absent in some individuals who have a good immunological and virological response to antiretroviral therapy [26, 27], particularly when HAART is started at low CD4 lymphocytes count [24]. However, when interpreting data on CD4 lymphocyte counts at the time of diagnosis of tuberculosis it should be taken into account that active tuberculosis itself can cause immunosuppression, as suggested by the transient decrease in CD4 lymphocytes observed in a significant proportion of HIV-negative patients with tuberculosis [28, 29].

Previous studies conducted in European countries have shown that among HIV-infected patients, being foreign born is an independent risk factor for tuberculosis [30, 31]. Foreignborn patients represent $34.4 \%$ of patients with tuberculosis in the present study, while Italian data for the same time period showed that foreign-born persons constitute $13.1 \%$ of reported AIDS cases [32] Thus, the current findings confirm that in industrialised countries, tuberculosis disproportionately affects HIV-infected foreign-born persons, and is in agreement with surveillance data showing that persons born abroad account for a high proportion, approximately one quarter, of the overall number of patients with tuberculosis reported in Italy in 2000 [33].

On the other hand, in this study, data were not collected on other environmental factors or associated medical conditions that may influence the risk of tuberculosis in HIV-infected persons.

Other limitations of the present study need to be taken into consideration. First, approximately one third of the Italian infectious disease hospital units did not participate in the study. However, participating units were located in all Italian regions and provided care to the majority of HIV-infected patients in Italy, as suggested by the fact that during the study period these units reported $65.2 \%$ of AIDS cases reported to the Italian AIDS registry (G. Rezza, Istituto Superiore di Sanità, Rome, Italy; personal communication). Second, although in Italy HIV-infected persons are usually cared for in infectious disease units, patients with HIV-associated tuberculosis, especially those who are first tested for HIV when diagnosed with tuberculosis, may also be admitted to other hospital units. Therefore, it is possible that the current authors have underestimated the proportion of patients who are diagnosed with HIV concurrently with tuberculosis diagnosis, as well as the proportion of HIV-infected patients on the overall number of tuberculosis cases. Thirdly, since participating units provided the number of HIV-infected persons under care but not the follow-up time for each person, the present authors were unable to assess the incidence of tuberculosis per person per year of follow-up. Fourthly, no information on actual adherence to antiretroviral therapy in patients to whom it was prescribed before tuberculosis was given.

In conclusion the current study shows that HIV-associated tuberculosis continues to occur when highly active antiretroviral therapy is widely used, although with a reduced frequency compared with the pre-highly active antiretroviral therapy era. To grasp the full potential impact of highly active antiretroviral therapy on the epidemic of HIV-associated tuberculosis in industrialised countries, it is necessary to improve the effectiveness of care for HIV-infected persons, in particular to promote early HIV testing for persons at risk and access to care for those testing positive. Clearly, tuberculosis control measures for HIV-infected persons, such as detection and treatment of latent tuberculosis infection, still remains important in the context of availability of highly active antiretroviral therapy.

\footnotetext{
Members of the Gruppo Italiano di Studio Tubercolosi e AIDS (GISTA) - Società Italiana di Malattie Infettive e Tropicali (SIMIT) study group and participating institutions. Regional coordinators: S. Babudieri (Sassari, "SS. Annunziata"); M. Bassetti, R. Rosso (Genova, "S. Martino"); S. Carbonara (Bari, "Policlinico"); S. Carradori (Ferrara, "Arcispedale S. Anna"); B.M. Celesia (Catania, "Ascoli-Tomaselli"); A. Chirianni (Napoli, "Cotugno"); G. Di Perri (Torino, "Amedeo di Savoia"); P. Fabietti (Vasto, "Presidio Ospedaliero di Vasto"); A. Gabbuti (Firenze, "S.M. Annunziata"); V. Guadagnino (Catanzaro, "Policlinico Mater Domini"); E. Iemoli (Milano, "Sacco"); V. Manfrin (Vicenza, "S. Bortolo"); A. Matteelli (Brescia, "Spedali Civili"); M.B. Pasticci (Perugia, "Policlinico Monteluce"); B. Salassa (Torino, "Amedeo di Savoia"); F. Zacchini (Grosseto, "O. Misericordia").

Participating persons and institutions: Ancona: F. Burzacchini, A. Giacometti ("Umberto I"); Aosta: A. Tassara, A. Traverso ("Ospedale Generale Regionale"); Arezzo: P. Giorni, ("S. Maria Sopra i Ponti"); Ascoli Piceno: M. Gobbi ("C.G. Mazzoni"); Avezzano: R. Mariani ("SS. Filippo e Nicola"); Aviano: G. Di Gennaro ("Centro di Riferimento Oncologico"); Barcellona Pozza di Gotto: L. Panella, ("S. Andrea"); Bisceglie: R. Losappio ("V. Emanuele II"); Bologna: C. Beltrami P. Costigliola, ("S. Orsola"), G. Fasulo ("C.A. Pizzardi"); Bolzano: O. Moling ("Ospedale Generale Regionale"); Brescia: D. Bertelli, S. Tedoldi ("Spedali Civili"); Brindisi: D. Potenza ("A. di Summa"); Cagliari: P.E. Manconi ("Policlinico"); Casa S. Erice: S. Zichichi ("S. Antonio Abate"); Caserta: C. Nacca ("Gruppo C"); Catania: F. Fatuzzo, R. La Rosa, ("V.E. Ferrarotto S. Bambino"), S. Galvagna ("Garibaldi"); Cesena: C. Grosso ("M. Bufalini"); Chieti: J. Vecchiet ("SS. Annunziata"); Como: E. Longoni ("S. Anna"); Cosenza: L. Guaglianone ("Ospedale di Cosenza");
} 
Cremona: A. Pan ("Istituti Ospitalieri"); Crotone: S. Pellicanò ("S. Giovanni di Dio"); Cuneo: G. Raineri ("S. Croce e Carle"); Foggia: S. Ferrara ("Ospedali Riuniti"); Frosinone: E. Anzalone, A. Gallo ("Umberto I"); Gallipoli: S. Cataldini ("Sacro Cuore di Gesù"); Genova: F. Dodi (S. Martino); Lamezia Terme: A. Petronio ("Ospedale Civile"); Latina: G. Salone ("S. Maria Goretti"); Lecce: E.P. De Luca Andrioli ("Vito Fazzi"); Legnago: G. De Checchi ("Ospedale Civile"); Legnano: M. Villa ("Ospedale Civile"); Livorno: R. Pardelli ("Ospedali Riuniti"); Lucca: A. Tardio ("Piana di Lucca"); Macerata: C. Urbani ("Ospedale Generale Provinciale"); Mantova: G. Gattuso ("C. Poma"); Massa: L. Matini ("Presidio Ospedaliero di Massa C."); Matera: G. Casciano ("Ospedale Provinciale"); Messina: F. Loschiavo ("Policlinico"); Milano: I. Errante ("Cà Granda-Niguarda"); G. Giani, P. Meraviglia, C. Molteni ("Sacco"); Modena: G. Guaraldi ("Policlinico"); Monza: S. Foresti ("S. Gerardo"); Napoli: N. Abbrescia, C. Izzo ("Cotugno"), P. Filippini ("Gesù e Maria"); S. Noce ("Policlinico Federico II"); Palermo: E.R. Dalle Nogare ("Casa del Sole Lanza di Trabia"); E. Farinella ("Malattie Infettive Guadagna"); Pavia: P. Sacchi, L. Scudeller ("S. Matteo"); Pesaro: E. Petrelli ("S. Salvatore"); Pescara: L. Alterio ("Presidio Ospedaliero"); Piacenza: F. Paolillo ("Presidio"); Pisa: E. Savalli, R. Doria ("Azienda Ospedaliera Pisana"); Pistoia: M. Catalani ("Spedali Riuniti"); Prato: M. Brizzi ("Misericordia e Dolce"); Ragusa: N. Storaci ("M.P. Arezzo"); Rieti: G.P. Natalini Raponi ("Ospedale Generale Provinciale"); Rimini: L.T. Martelli ("Ospedale per gli Infermi"); Roma: S. Grisetti, S. Lanini, F. Palmieri ("Spallanzani"); P. Santopadre ("Policlinico Umberto I"); Schio: F. Marranconi ("Ospedale Civile"); Siena: M. Rubino ("Spedali Riuniti"); Taranto: M.A. Rollo ("SS. Annunziata"); Teramo: D. Di Giammartino ("Ospedale Civile"); Terni: C. Di Giuli ("S. Maria"); Torino: M.F. Bianco Chinto, F. Gaiottino, C. Preziosi, A. Zeme ("Amedeo di Savoia"); Triggiano: C. Fico ("F. Fallacara"); Varese: F. Di Natale (Ospedale di Circolo); Verbania: C. Sfara ("Ospedale Civile di Verbania"); Vercelli: M. Gobber ("S. Andrea di Vercelli").

\section{References}

1. Centers for Disease Control and Prevention. Targeted tuberculin testing and treatment of latent tuberculosis infection. $M M W R$ 2000; 49 (No. RR-6): 1-43.

2. Girardi E, Antonucci G, Vanacore P, et al. Impact of combination antiretroviral therapy on the risk of tuberculosis among persons with HIV infection. AIDS 2000; 14: 1985-1991.

3. Jones JL, Hanson DL, Dworkin MS, DeCock KM. HIVassociated tuberculosis in the era of highly active antiretroviral therapy. Int J Tuberc Lung Dis 2000; 4: 1026-1031.

4. Santoro-Lopes G, de Pinho AM, Harrison LH, Schechter M. Reduced risk of tuberculosis among Brazilian patients with advanced human immunodeficiency virus infection treated with highly active antiretroviral therapy. Clin Infect Dis 2002; 34: 543-546.

5. Badri M, Wilson D, Wood R. Effect of highly active antiretroviral therapy on incidence of tuberculosis in South Africa: a cohort study. Lancet 2002; 359: 2059-2064.

6. Jones JL, Hanson DL, Dworkin MS, et al. Surveillance for AIDS-defining opportunistic illnesses, 1992-1997. MMWR 1999; 48 (No. SS-2): 1-22.

7. Kirk O, Gatell JM, Mocroft A, et al. Infections with
Mycobacterium tuberculosis and Mycobacterium avium among HIV-infected patients after the introduction of highly active antiretroviral therapy. Am J Respir Crit Care Med 2000; 162: 865-872.

8. Wagner TM, Pezzotti P, Valdarchi C, Rezza G. Different pattern of AIDS-defining diseases in persons responding to highly active antiretroviral therapy. J Acquir Immune Defic Syndr 2001; 26: 394-395.

9. Girardi E, Vanacore P, Palmieri F, et al. Outcome of treatment of HIV-associated tuberculosis in the era of HAART. Program and abstracts of the XIV International AIDS Conference; July 7-12, 2002; Barcelona, Spain. Abstract ThPeB7268. Barcelona, Prous Science, S.A., 2002.

10. Antonucci G, Girardi E, Armignacco O, Salmaso S, Ippolito $\mathrm{G}$, and GISTA. Tuberculosis in HIV-infected subjects in Italy: a multicentre study. AIDS 1992; 6: 1007-1013.

11. Ministero della Salute. Bollettino Epidemiologico. www. ministerosalute.it/promozione/malattie/bollettino.jsp. Date last accessed: December 202003.

12. Antonucci G, Girardi E, Raviglione M, et al. Guidelines of tuberculosis preventive therapy for HIV-infected persons: a prospective, multicentre study. Eur Respir J 2001; 18: 369_ 375.

13. Sackoff JE, Torian LV, Frieden TR, Brudney KF, Menzies IB. Purified protein derivative testing and tuberculosis preventive therapy for HIV-infected patients in New York City. AIDS 1998; 12: 2017-2023.

14. Brudney K, Dobkin J. Resurgent tuberculosis in New York City. Human immunodeficiency virus, homelessness, and the decline of tuberculosis control programs. Am Rev Respir Dis 1991; 144: 745-749.

15. Sackoff J, Bernard MA, Adams L. HIV-associated tuberculosis in the era of highly active antiretroviral therapy. Int $J$ Tuberc Lung Dis 2001; 5: 489.

16. Dean GL, Edwards SG, Ives NJ, et al. Treatment of tuberculosis in HIV-infected persons in the era of highly active antiretroviral therapy. AIDS 2002; 16: 75-83.

17. Girardi E, Sampaolesi A, Gentile M, Nurra G, Ippolito G. Increasing proportion of late diagnosis of HIV infection among patients with AIDS in Italy following introduction of combination antiretroviral therapy. J Acquir Immune Defic Syndr 2000; 25: 71-76.

18. Castilla J, Sobrino P, De La Fuente L, Noguer I, Guerra L, Parras F. Late diagnosis of HIV infection in the era of highly active antiretroviral therapy: consequences for AIDS incidence. AIDS 2002; 16: 1945-1951.

19. Puro V, D'Ubaldo C, Aloisi MS, Sherr L, Ippolito G. Temporal trends in reasons for and results of HIV-testing among women in Rome, Italy. Eur J Epidemiol 1998; 14: 433-437.

20. Rezza G. Andamento dell'infezione da HIV nei tossicodipendenti afferenti ai servizi di assistenza (SER.T.) in Italia [Trends of HIV infection in intravenous drug users cared for in public centres in Italy]. Rapporti ISTISAN, 1995; ii (95/ 41): $27-28$.

21. Centers for Disease Control and Prevention. Guidelines for using antiretroviral agents among HIV-infected adults and adolescents: recommendations of the Panel on Clinical Practices for Treatment of HIV. MMWR 2002; 51 (No. RR-7): 1-55.

22. Kaplan JE, Hanson D, Dworkin MS, et al. Epidemiology of human immunodeficiency virus-associated opportunistic infections in the United States in the era of highly active antiretroviral therapy. Clin Infect Dis 2000; 30: S5-S14.

23. Hanson DL, Chu SY, Farizo KM, Ward JW. Distribution of CD4+ T lymphocytes at diagnosis of acquired immunodeficiency syndrome-defining and other human immunodeficiency virus-related illnesses. Arch Intern Med 1995; 155: $1537-1542$.

24. Antonucci G, Girardi E, Raviglione MC, Ippolito G. Risk factors for tuberculosis in HIV-infected subjects. A prospective cohort study. JAMA 1995; 274: 143-148. 
25. Autran B, Carcelain G, Li TS, et al. Positive effects of combined antiretroviral therapy on CD4+ T cell homeostasis and function in advanced HIV disease. Science 1997; 277: $112-116$.

26. Hsieh SM, Hung CC, Pan SC, et al. Restoration of cellular immunity against tuberculosis in patients coinfected with HIV-1 and tuberculosis with effective antiretroviral therapy: assessment by determination of CD469 expression on T cells after tuberculin stimulation. J Acquir Immune Defic Syndr 2000; 25: 212-220.

27. Schluger NW, Perez D, Liu YM. Reconstitution of immune responses to tuberculosis in patients with HIV infection who receive antiretroviral therapy. Chest 2002; 122: 597-602.

28. Turett GS, Telzak EE. Normalization of CD4+ T-lymphocyte depletion in patients without HIV infection treated for tuberculosis. Chest 1995; 107: 589-592.

29. Jones BE, Oo MM, Taikwel EK, et al. CD4 cell counts in human immunodeficiency virus-negative patients with tuberculosis. Clin Infect Dis 1997; 24: 988-991.

30. Del Amo J, Petruckevitch A, Phillips AN, et al. Risk factors for tuberculosis in patients with AIDS in London: a casecontrol study. Int J Tuberc Lung Dis 1999; 3: 12-17.

31. Sudre P, Hirschel B, Toscani L, Ledergerber B, Rieder HL. Risk factors for tuberculosis among HIV-infected patients in Switzerland. Swiss HIV Cohort Study. Eur Respir J 1996; 9: 279-283.

32. Centro Operativo AIDS. Aggiornamento dei casi di AIDS notificati in Italia al 30 giugno 2003 [AIDS cases reported in Italy to 30 June, 2003]. Not Ist Super Sanità 2003; 16 (Suppl 1): $2-18$.

33. EuroTB (InVS/KNCV) and the national coordinators for tuberculosis surveillance in the WHO European Region. Surveillance of tuberculosis in Europe. Report on tuberculosis cases notified in 2000. Saint-Maurice, France, Institut de Veille Sanitaire, March 2003. 